\title{
DETERMINATION, INTERPRETATION AND MODELING OF CHLORINATION BY-PRODUCTS CONCENTRATIONS IN SURFACE WATERS
}

\section{A. NIKOLAOU 1 ,* \\ G. ARHONDITSIS ${ }^{2}$ \\ V. KOLOVOYIANNIS 3 \\ S. GOLFINOPOULOS 1}

\section{T.D. LEKKAS 1}

${ }^{1}$ University of the Aegean, Department of Environmental Studies Water and Air Quality Laboratory University Hill, 81100 Mytilene, Greece

2 University of Washington, Department of Civil and Environmental Engineering $313 B$ More Hall, Box 352700, Seattle, Washington, USA

${ }^{3}$ University of the Aegean, Department of Marine Sciences University Hill, 81100 Mytilene, Greece
Selected from papers presented at the $8^{\text {th }}$ Conference on Environmental Science and Technology, 8 - 10 September 2003, Lemnos, Greece. *to whom all correspondence should be addressed: Tel: + (30) 22510 36225-7, fax: +(30) 22510-36226 e-mail: nnikol@aegean.gr

\begin{abstract}
The formation of chlorination by-products (CBPs) was investigated by bench-scale chlorination experiments with surface waters from different sources in Lesvos island, Greece. The main factors studied were organic matter content of water (expressed as UV-272 absorbance), time and chlorine dose. The CBPs, determined by gas chromatographic techniques, belong to the categories of trihalomethanes (THMs), haloacetic acids (HAAs), haloacetonitriles, chloral hydrate and chloropicrin. HAAs and THMs were the most abundant CBPs detected in the chlorinated samples, while haloketones, haloacetonitriles and chloral hydrate occurred at much lower concentrations. Statistical analysis of the results with multifactor analysis of variance revealed the influence of the parameters studied on the formation of individual compounds. Application of principal component analysis (PCA) provided a clear picture of the differentiations between varying water sources and chlorination conditions. Multiple regression was used for development of predictive models for CBPs formation. The proposed models are considered satisfactory for predicting CBPs concentrations for water sources and chlorination conditions similar to those examined.
\end{abstract}

KEYWORDS: chlorination by-products, multifactor analysis of variance, principal component analysis, multiple regression models

\section{INTRODUCTION}

Water chlorination has been reported to result in the formation of a large number of compounds, known as chlorination by-products (CBPs) 
(Rook, 1974; Nikolaou et al., 1999; Richardson, 2003), including trihalomethanes (THMs), haloacetic acids (HAAs), chloral hydrate $(\mathrm{CH})$, haloacetonitriles, haloketones and chloropicrin. Scientific interest about CBPs has increased during the last decades, due to the adverse health effects they may have on human beings. The health effects for most of the CBPs detected so far in chlorinated waters are still under investigation. On the basis of current knowledge, a number of CBPs have been regulated by EPA, WHO and the European Union (EPA, 1996; WHO, 1995; EC, 1998).

The formation of CBPs is affected by chlorine dose and residual, natural organic matter (NOM), bromide ion $(\mathrm{Br})$, contact time, $\mathrm{pH}$ and temperature. Increase in chlorine dose and in NOM concentration enhance formation of CBPs, while increase in bromide ion concentration shifts the speciation of CBPs formed to more brominated than chlorinated compounds (Singer, 1994; Cooper et al., 1985; Cowman and Singer, 1996). Contact time, $\mathrm{pH}$ and temperature can affect the formation of individual categories of CBPs in a different manner. Particularly, different effect of contact time has been reported on different categories of CBPs; THMs and HAAs increase with time, while volatile CBPs such as haloacetonitriles and haloketones decrease due to hydrolysis and reactions with residual chlorine (Singer, 1994; Lekkas, 2003; Nikolaou et al., 2004). Increase of $\mathrm{pH}$ leads to rapid decomposition of haloketones, but also to increased formation of THMs. Some HAAs species have been reported to increase at low $\mathrm{pH}$. Elevated temperature gives higher yields of CBPs due to increased reaction kinetics, while decomposition of dihaloacetonitriles and haloketones is also enhanced during temperature increase (Singer, 1994; Nikolaou et al., 2001).

The aim of the present investigation was the identification of the effects of the factors mentioned, and especially NOM content (measured as UV-272 $\mathrm{nm}$ ), chlorine dose and contact time, on the formation of representative compounds belonging to different categories of CBPs. For this purpose, the concentrations of CBPs were determined in chlorinated surface water samples. The compounds studied belong to the categories of THMs (chloroform- $\mathrm{CHCl}_{3}$, dichlorobromomethane- $\mathrm{CHCl}_{2} \mathrm{Br}$, dibromochloro-methane$\mathrm{CHClBr}_{2}$, bromoform- $\mathrm{CHBr}_{3}$ ), HAAs (mono- chloroacetic acid-MCA, monobromoacetic acidMBA, dichloroacetic acid-DCA, bromochloroacetic acid-BCA, trichloroacetic acid-TCA, bromodichloroacetic acid-BDCA, dibromochloroacetic acid-DBCA, tribromoacetic acid-TBA), haloacetonitriles (monochloroacetonitrile-MCAN, dichlo-roacetonitrile-DCAN, trichloroacetonitrile-TCAN, bromochloroacetonitrile-BCAN, dibromoacetonitrile-DBAN), haloketones (1,1-dichloropropanone-1,1-DCP, 1,1,1-trichloro-propanone-1,1,1-TCP, 1,3dichloropropanone-1.3-DCP), chloral hydrate $(\mathrm{CH})$ and chloropicrin (CP). The statistical analysis of the results, included analysis of variance and principal component analysis. Finally, multiple regression models were developed for the prediction of the concentrations of CBPs based on the particular chlorination conditions.

\section{EXPERIMENTAL \\ Glassware}

The glassware used during analysis was washed with detergent, rinsed with tap water, ultrapure water (Millipore: Milli-Ro 5 plus and Milli Q plus 185), acetone (Mallinckrodt Chemical Works St. Louis) and dried in an oven at $150{ }^{\circ} \mathrm{C}$ for 2 hours.

\section{Reagents-Standard Solutions}

Methanol (purge and trap grade) was purchased from Sigma-Aldrich, methyl-tert-butyl ether (MTBE) suprasolv grade, potassium dichromate, potassium iodide, potassium bromide, sodium sulfite, sodium sulfate, copper (II) sulfate pentahydrate and sulfuric acid concentrated ISO for analysis from Merck and boric acid (analytical grade) from Ferak. Ultrapure water was from a Milli-Q water purification system (Millipore: Milli-Ro 5 plus and Milli Q plus 185). Stock solutions of volatile CBPs were prepared in methanol by addition of certified CBPs standards (Chemservice, purity $>99 \%$ ). Stock solutions of the nine haloacetic acids (HAAs) and their methyl esters in methyl-tert-butyl ether (MTBE) were purchased from Supelco and were accompanied with certificates of analysis (purity > 99\%). All stock solutions were stored at $4{ }^{\circ} \mathrm{C}$.

From the stock solutions, standard solutions of CBPs $100 \mathrm{mg} \mathrm{l}^{-1}$ in MTBE were prepared, known volumes of which were injected into ultrapure water, giving standard solutions for system calibration. 


\section{Sampling-Chlorination}

Surface waters rich in organic matter were selected for this study, in order to provide a high potential of formation of a variety of CBPs which would allow investigation of their behavior. Water samples were collected in March 2000 from three rivers (Evergetoulas, Mylopotamos and Tsiknias) and two springs (Karini and Lampou Myli) in Mytilene, Greece, stored in 1-1 amber glass vials and transported to the Water and Air Quality Laboratory of the University of Aegean. There, $\mathrm{pH}$ measurements and sample filtration were performed, as well as analyses for chloride, bromide and nitrate ions by ion chromatography method (O'Dell et al., 1984). UV absorbance measurements were carried out at $272 \mathrm{~nm}(\mathrm{UV}-272)$ by use of a Cary 1E UV-visible spectrophotometer with $1-\mathrm{cm}$ quartz cells. UV-272 was measured instead of Total Organic Carbon (TOC) as an indicator of the organic matter content of the samples, because it has been reported to be an equivalent or better indicator than TOC, especially when the quenching agent sulfite exists in the water sample (Eaton, 1995; Korshin et al., 1997).

Chlorination of the samples was performed according to the procedure described in Standard Methods for the Examination of Water and Wastewater. Chlorine dosages ranged from 2 to $30 \mathrm{mg} \mathrm{l}^{-1}$. The chlorinated samples were divided into 40-ml amber glass bottles with polypropylene screw caps and TFE-faced septa and were stored at room temperature $\left(20^{\circ} \mathrm{C}\right)$ until the desired contact times, ranging from 0 to $72 \mathrm{~h}$, were fulfilled. Then, the chlorination reaction was terminated by addition of sodium sulfite (100 mg per liter of sample) for quenching of residual chlorine.

\section{Sample preparation}

For volatile CBPs, a modification of EPA Method 551.1 was performed, which includes Liquid Liquid Extraction (LLE) with MTBE, after addition of anhydrous sodium sulfate (Nikolaou et al., 2002a). For HAAs, acidic methanol esterification was used, which includes acidification to $\mathrm{pH}<$ 0.5 , addition of anhydrous sodium sulfate and copper sulfate pentahydrate, LLE with MTBE and derivatization with solution of sulfuric acid in methanol (Nikolaou et al., 2002b).

\section{Instrumentation and analytical conditions}

A Hewlett Packard Gas Chromatograph (GC) 5890 Series II with a ${ }^{63} \mathrm{Ni}$ Electron Capture Detector (ECD) was used. The carrier gas was $\mathrm{He}$ and the make-up gas N2. The column used was fused silica DB-1, $30 \mathrm{~m}$ x $0.32 \mathrm{~mm}$ i.d. x $0.25 \mu \mathrm{m}$ film thickness. The injection technique was split/splitless. The analytical conditions of the GC are presented in Table 1.

Recoveries ranged from $87.6 \%$ to $112.8 \%$ for THMs, from $60.4 \%$ to $144.5 \%$ for the other CBPs and from $78.1 \%$ to $123.7 \%$ for HAAs. The DLs (estimated for signal-to-noise ratio 3:1) ranged from $0.005 \mu \mathrm{g} \mathrm{l}^{-1}$ to $0.070 \mu \mathrm{g} \mathrm{l}^{-1}$ for the volatile CBPs and from $0.01 \mu \mathrm{g} \mathrm{l}^{-1}$ to $0.2 \mu \mathrm{g} \mathrm{l}^{-1}$ for HAAs. A Hewlett Packard Mass Selective Detector 5971, was used for confirmation.

Table 1. Analytical conditions for the determination of CBPs

\begin{tabular}{lc}
\hline Parameter & Value \\
\hline Carrier gas flow: & $1.6 \mathrm{ml} / \mathrm{min}$ \\
Oven temperature: & $35{ }^{\circ} \mathrm{C} \quad(9 \mathrm{~min})$, with \\
& $1 \mathrm{oC} / \mathrm{min}$ to $40{ }^{\circ} \mathrm{C}(3 \mathrm{~min})$, \\
& with $6{ }^{\circ} \mathrm{C} / \mathrm{min}$ to $220^{\circ} \mathrm{C}(10 \mathrm{~min})$ \\
Injector temperature: & $175^{\circ} \mathrm{C}$ \\
Split ratio: & $1: 25$ \\
Detector temperature: & $300^{\circ} \mathrm{C}$ \\
\hline
\end{tabular}

\section{STATISTICAL ANALYSIS}

For the analysis of the experimental results, multifactor analysis of variance was applied, by using Statgraphics 4.0. We determined the existence of statistically significant influence of the studied factors on CBP formation, and in addition the existence of significant interactions between factors (Zar, 1984), i.e. whether some combinations of factors' levels have statistically significant effect on CBP formation. For the CBPs showing statistically significant difference regarding the factors tested, Least Significant Difference (LSD) tests were applied to determine the sub-groups of data belonging to statistically different populations. Principal Component Analysis (PCA) was also applied (Pielou, 1984), by use of SPSS 1999, in order to determine the different groups of data obtained with the different combinations of chlorination conditions.

Multiple regression was used for development of predictive models for CBPs formation. Before the development of models, variables were tested for deviations from the normal distribution and 
transformations (logarithmic or square root transformation) were applied wherever necessary (Golfinopoulos et al., 1998). The Statistica 1999 software was used for the development of multiple regression models. The correlations between all variables were examined to determine possible existence of correlations between the predictor variables, and thus avoid problems of multicollinearity. For the elimination of statistically insignificant variables, the F-criterion was used, based on the ratio of the sum of squares due to regression (SSreg) to the sum of squares of residuals divided by the corresponding degrees of freedom $\left(\mathrm{se}^{2}\right)$. For each regression coefficient, $\mathrm{F}=\mathrm{SSreg} / \mathrm{se}^{2}$. High $\mathrm{F}$ values denote that the particular coefficient is statistically significant, and thus the variable must be included in the model (Golfinopoulos et al., 1998).

\section{RESULTS AND DISCUSSION Formation of CBPs in the chlorinated samples}

The rivers of Mytilene are small and the flow is not continuous throughout the year, due to the warm summer months. Therefore, their water is rich in organic matter content. The highest UV272 absorbance was observed in river Mylopotamos $\left(0.249 \mathrm{~cm}^{-1}\right)$, where also the concentrations of chloride and bromide ions were high (138.9 and $2.4 \mathrm{mg} \mathrm{l}^{-1}$ respectively). The sampling point at this river is located near a saltwork. Rivers Evergetoulas and Tsiknias showed significantly lower UV-absorbance and chloride concentration than river Mylopotamos, and not detectable concentration of bromide ion. UVabsorbance in spring water samples was very low (0.004- $\left.0.005 \mathrm{~cm}^{-1}\right)$.

In the raw water samples, none of the compounds studied were detected. On the contrary, in chlorinated samples, many compounds were present: chloroform, dichloro-bromomethane, dibromochloromethane, bromoform, $\mathrm{CH}, 1,1-\mathrm{DCP}$, 1,1,1-TCP, BCAN, DBAN, MCA, MBA, DCA, BCA, TCA, DBA, BDCA, DBCA, TBA. A representative GC-ECD chromatogram of HAAs in a chlorinated sample from Evergetoulas river is presented in Figure 1. The range of concentrations of CBPs detected in all chlorinated samples is presented in Table 2 .

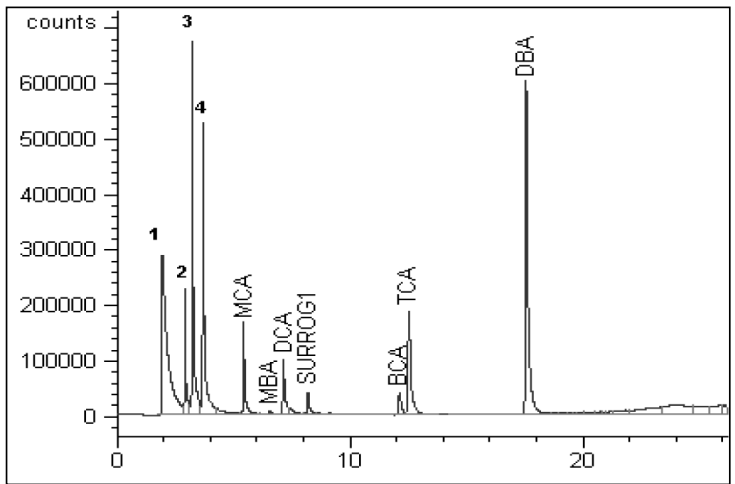

Figure 1: GC-ECD chromatogram of HAAs in chlorinated sample from river Evergetoulas (chlorine dose $20 \mathrm{mg} \mathrm{l}^{-1}$, reaction time $16 \mathrm{~h}$ ). 1: MTBE, 2: $\mathrm{CHCl}_{3}, 3: \mathrm{CHCl}_{2} \mathrm{Br}, 4: \mathrm{CHClBr}_{2}$, SURROG1: Surrogate standard, 2-bromopropionic acid

Table 2. Range of CBPs concentrations detected in the chlorinated samples

\begin{tabular}{lc}
\hline $\mathbf{C B P s}$ & Concentration range $\left(\boldsymbol{\mu g} \mathbf{l}^{-\mathbf{1}}\right)$ \\
\hline $\mathrm{CHCl}_{3}$ & $n d-178.69$ \\
$\mathrm{CHCl}_{2} \mathrm{Br}$ & $n d-61.68$ \\
$\mathrm{CHClBr}_{2}$ & $n d-128.64$ \\
$C H B r_{3}$ & $n d-558.11$ \\
$C H$ & $n d-2.08$ \\
$1,1-D C P$ & $n d-2.27$ \\
$1,1,1-T C P$ & $n d-1.87$ \\
$1,3-D C P$ & $n d$ \\
$B C A N$ & $n d-4.11$ \\
$D B A N$ & $n d-8.38$ \\
$M C A N$ & $n d-0.39$ \\
$D C A N$ & $n d-2.37$ \\
$T C A N$ & $n d$ \\
$C P$ & $n d$ \\
$M B A N$ & $n d$ \\
$M C A$ & $n d-217.64$ \\
$M B A$ & $n d-3.82$ \\
$D C A$ & $n d-63.99$ \\
$B C A$ & $n d-26.56$ \\
$T C A$ & $n d-32.8$ \\
$D B A$ & $n d-99.67$ \\
$B D C A$ & $n d-22.91$ \\
$D B C A$ & $n d-14.91$ \\
$T B A$ & $n d-8.38$ \\
\hline$n d:-D t$ &
\end{tabular}

nd: not detectable concentration

HAAs and THMs were the most abundant substances, while the other CBPs (haloacetonitriles, haloketones, chloral hydrate) occurred at much lower concentrations. In most instances, chlorinated species (chloroform, MCA, DCA, TCA) pre- 
dominated, however in the case of Mylopotamos, water with high bromide content, the brominated species bromoform and DBA were formed in significantly higher concentrations.

In samples from Evergetoulas and Tsiknias rivers, the dominant species of volatile CBPs was chloroform, followed by dichlorobromomethane and dibromochloromethane. 1,1-DCP was detected only at zero time, because it rapidly forms as soon as the water is chlorinated, but it also rapidly decomposes. 1,1,1-TCP decomposed with a slower rate; its concentration increased until 4 hours after chlorination and decreased after 16 hours. A variety of HAAs were also detected in chlorinated samples from Evergetoulas and Tsiknias rivers. The major species was MCA followed by TCA, DBA, BCA at low chlorine doses and by TCA, DCA, BCA, DBA at higher chlorine doses, which confirms that a higher chlorine dose increases formation of chlorinated species over brominated ones.

For chlorinated water from Mylopotamos river, different speciation of CBPs was observed, as mentioned above, with bromoform being the most abundant compound formed followed by dibromochloromethane and dichlorobromomethane. Chloroform did not form. This is due to high bromide concentration in the water of this river $\left(2.4 \mathrm{mg} \mathrm{l}^{-1}\right) .1$ 1-DCP formed again only at zero time and then disappeared, while $\mathrm{CH}$ formed only at zero time and only when higher chlorine doses were applied. DBAN was also formed, with higher concentration at lower chlorine dose. Enhanced formation of brominated species was observed for HAAs as well. DBA con- centration was significantly higher than TBA and BCA concentrations. For high chlorine doses, BCA concentration became higher than TBA concentration, because a higher chlorine dose supports formation of chlorinated species. DCA was formed only at high chlorine doses.

In chlorinated water samples from Karini spring, the same pattern as in river Tsiknias was observed, while in samples from Lampou Myli spring, brominated species concentrations were elevated, due to presence of bromide.

\section{Multifactor analysis of variance results}

For application of multifactor analysis of variance, the following 5 levels of UV-272 absorbance values were defined:

A) Samples from springs Karini and Lampou Myli (0.004 xol $0.005 \mathrm{~cm}^{-1}$ respectively)

B) Samples from river Evergetoulas $\left(0.029 \mathrm{~cm}^{-1}\right)$

C) Samples from river Tsiknias $\left(0.069 \mathrm{~cm}^{-1}\right)$

D) Samples from river Mylopotamos $\left(0.139 \mathrm{~cm}^{-1}\right)$. Multifactor analysis of variance was applied for three factors: UV-272, time and chlorine dose. The results (for the CBPs showing statistically significant differences) are shown in Table 3.

$\mathrm{CHCl} 3$ formation was significantly affected from all three parameters studied, with statistically significant interactions UV272-Cl dose and UV272time. The highest $\mathrm{CHCl}_{3}$ concentrations were formed at UV272 levels B and C, moderate at level $\mathrm{A}$ and the lowest at $\mathrm{D}$, in spite of the high UV272 value for the latter location. The presence of high concentrations of $\mathrm{Br}$ - in samples from this location leads to predominance of brominated

Table 3. Multifactor analysis of variance results for the CBPs concentrations as function of UV-272, chlorine dose and reaction time

\begin{tabular}{|c|c|c|c|c|c|c|}
\hline \multirow[t]{2}{*}{ CBPs } & \multirow{2}{*}{$\begin{array}{l}\text { Parameters } \\
\text { UV272 }\end{array}$} & \multirow[b]{2}{*}{ Chlorine dose } & \multirow[b]{2}{*}{ Time } & \multicolumn{3}{|c|}{ Parameter interactions } \\
\hline & & & & UV272-Cl dose & UV272-time & $\mathrm{Cl}$ dose-time \\
\hline $\mathrm{CHCl}^{3}$ & $*$ & $*$ & $*$ & $*$ & $*$ & \\
\hline $\mathrm{CHCl}^{2} \mathrm{Br}$ & $*$ & $*$ & $*$ & & $*$ & \\
\hline $\mathrm{CHClBr}^{2}$ & $*$ & $*$ & $*$ & * & $*$ & \\
\hline $\mathrm{CHBr} r^{3}$ & $*$ & & $*$ & $*$ & $*$ & \\
\hline $\mathrm{CH}$ & $*$ & & $*$ & & & \\
\hline $1,1,1-T C P$ & $*$ & & * & & & \\
\hline$M C A$ & & & $*$ & & $*$ & \\
\hline$D C A$ & $*$ & $*$ & $*$ & & $*$ & $*$ \\
\hline$B C A$ & $*$ & $*$ & $*$ & & $*$ & \\
\hline$T C A$ & $*$ & $*$ & $*$ & & $*$ & \\
\hline$D B A$ & & & $*$ & & $*$ & \\
\hline
\end{tabular}

*: Statistically significant difference (significance level $<0.05$ ) 
species, mainly $\mathrm{CHBr}_{3}$ and DBA. $\mathrm{CHCl}_{3}$ formation increased with time and $\mathrm{Cl}$ dose.

$\mathrm{CHCl}_{2} \mathrm{Br}$ concentration was also significantly affected from all the parameters studied, with statistically significant interaction UV272-time. Higher concentrations were formed for UV272 levels B and C and lower at level A (low UV272 values). Moderate concentrations were observed for level $\mathrm{D}$, due to presence of bromide ion, as mentioned above. $\mathrm{CHCl}_{2} \mathrm{Br}$ formation was significantly enhanced from increasing contact time and chlorine dose. The formation of $\mathrm{CHClBr}_{2}$ showed statistically significant differences as function of all studied parameters, with UV272chlorine dose and UV272-time interactions. $\mathrm{CHClBr}_{2}$ levels were observed in parallel with UV272 levels, with the highest concentrations being formed at UV272 level D, lower at C and B, and the lowest at level $\mathrm{A}$. The combination of high UV272 values and high $\mathrm{Br}$ - concentrations enhanced the formation of this brominated species of CBPs. The same is true for bromoform. $\mathrm{CH}$ formation was significantly affected from UV272 and reaction time. Higher concentrations were observed in samples with UV272 levels A and $\mathrm{B}$ than $\mathrm{D}$, since $\mathrm{CH}$ (non-brominated by-product) formation preferably occurs in absence of $\mathrm{Br}$. Positive influence of reaction time on $\mathrm{CH}$ formation was also observed during the first $16 \mathrm{~h}$. The formation of 1,1,1-TCP showed the same trends with $\mathrm{CH}$ regarding UV272. However, decomposition of this compound over time was observed.

MCA formation was significantly affected only from time, with rapid formation within the first 4 hours. DCA formation was significantly affected from all three parameters, with interactions UV272-time and chlorine dose-time. Higher DCA concentrations were detected in samples with UV272 levels B and C. DCA formation was also rapid within the first 4 hours. The formation of TCA showed similar trends with that of DCA. DBA formation was significantly affected only from time, with rapid formation during the first hours of the reaction. Finally, for BCA, the statistically significant parameters were UV272 and time. The highest concentration of BCA was detected in chlorinated water from river Mylopotamos (high UV272, high NOM content). BCA formation increased with time.

\section{Principal Component Analysis (PCA) results}

Principal component analysis (PCA) was applied for the chlorinated samples from rivers Evergetoulas, Mylopotamos and Tsiknias, in order to observe the differentiation between water sources and chlorination conditions, and the results are presented in Fig. 2.

The results showed the existence of three groups in the case of Fig. 2a and five groups in the case of Fig. 2b. Water samples from rivers Tsiknias and Evergetoulas (Fig. 2a, group A) and from river Tsiknias (Fig. 2b, group A) were in both cases separately grouped from those from river Mylopotamos (groups B, C, D, E). This is due to the different properties of the natural waters regarding UV272 and bromide ion. Moreover, for samples from Mylopotamos, sub-groups related to chlorine dose were observed: group $\mathrm{B}(\mathrm{Cl}$ dose 5 $\left.\mathrm{mg} \mathrm{l}^{-1}\right)$ and group $\mathrm{C}\left(\mathrm{Cl}\right.$ dose $\left.20 \mathrm{mg} \mathrm{l}^{-1}\right)$ in the case of Fig. 2a, and group $\mathrm{B}\left(\mathrm{Cl}\right.$ dose $3 \mathrm{mg}{ }^{\mathrm{l}-1}$, reaction time $48 \mathrm{~h})$ group $\mathrm{C}\left(\mathrm{Cl}\right.$ dose $15 \mathrm{mg} \mathrm{l}^{-1}$, reaction time $48 \mathrm{~h}$ ), group $\mathrm{D}\left(\mathrm{Cl}\right.$ dose $3,7.5$ and $\left.15 \mathrm{mg} \mathrm{l}^{-1}\right)$ and group $\mathrm{E}\left(\mathrm{Cl}\right.$ dose $\left.30 \mathrm{mg} \mathrm{l}^{-1}\right)$ in the case of Fig. $2 \mathrm{~b}$.

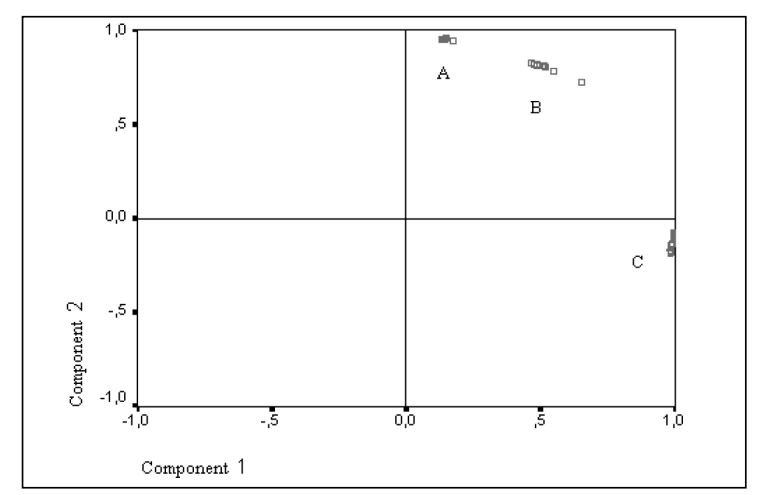

(a) Rivers Evergetoulas, Mylopotamos and Tsinkias, chlorine doses 5 and $20 \mathrm{mg} \mathrm{l}^{-1}$

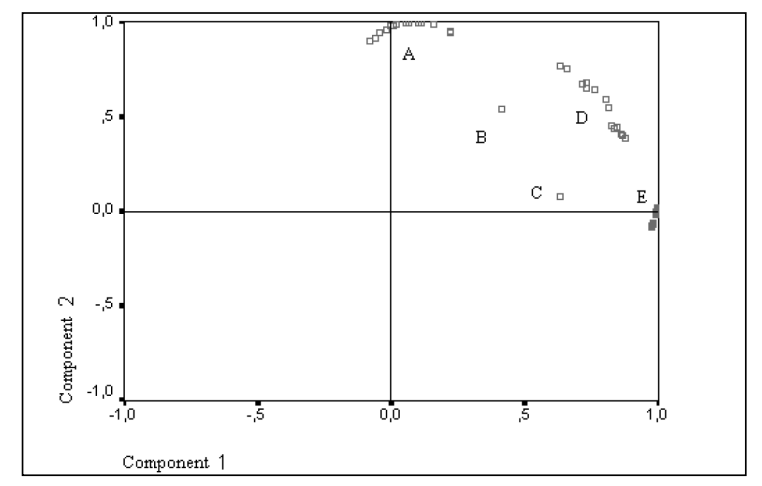

(b) Rivers Mylopotamos and Tsiknias, chlorine doses 3, $7.5,15,30 \mathrm{mgl}^{-1}$

Figure 2: PCA results for chlorinated river water samples 
Table 4. Summary statistical evaluation of the multiple regression models

\begin{tabular}{lccccc}
\hline Model & $\mathbf{N}$ & $\mathbf{F}$ & $\mathbf{R 2}$ & Standard error of estimate & Durbin-Watson estimate \\
\hline$T H M s$ & 94 & $F(4,90)=1993.7>F_{0.01}=3.48$ & 0.70 & 0.21 & 2.15 \\
$H A A s$ & 109 & $F(4,87)=510.32>F_{0.01}=3.48$ & 0.40 & 0.49 & 1.77 \\
\hline
\end{tabular}

\section{Multiple regression models}

Multiple regression models were developed on the basis of the results of the present study, for the concentrations of THMs and HAAs. The concentration values of THMs and HAAs are expressed in $\mu \mathrm{g} \mathrm{l}^{-1}$, UV272 in $\mathrm{cm}^{-1}$, chlorine dose in $\mathrm{m} \mathrm{l}^{-1}$ and reaction time in $\mathrm{h}$.

$\log \mathrm{THMs}=0.487 \log \mathrm{UV} 272+0.921 \log \mathrm{H}+0.1931$ ogtime $+0.355 \log$ Cldose (1)

$\log$ HAAs $=0.279 \log \mathrm{UV} 272+0.578 \log \mathrm{H}+0.2951$

ogtime $+0.411 \log$ Cldose (2)

A summary statistical evaluation of these models is presented in Table 4.

The proposed models can provide satisfactory estimations of THMs and HAAs concentrations formed under the chlorination conditions studied. The percentage of observed concentrations within $\pm 20 \%$ of the predicted concentration values was $90 \%$ for the THM model and $70 \%$ for the HAA model (Nikolaou et al., 2002c).

Application of the present models for other waters with similar properties, as well as evaluation with data from a water treatment plant consist the future developments of the present work. These two objectives will enable the testing of the applicability range of the proposed models, and the estimation of correction factors that possibly necessitate to obtain accurate predictions of the formation of CBPs during chlorination.

\section{CONCLUSIONS}

Chlorination of natural water samples resulted in the formation of many CBPs. HAAs and THMs were the most abundant substances, while haloacetonitriles, haloketones, $\mathrm{CH}$ occurred at much lower concentrations.

The factors NOM, reaction time and chlorine dose affected the concentrations of different categories of CBPs significantly and in some cases differently. Increase in chlorine dose resulted in formation of higher concentrations of CBPs in all cases. However, the influence of reaction time was different on different categories of CBPs, with longer reaction time resulting in higher concentrations of THMs and HAAs, but in lower concentrations of haloketones and haloacetonitriles.

The influence of the parameters studied on the formation of individual compounds was confirmed by statistical analysis of the results with multifactor analysis of variance and principal component analysis (PCA).

Multiple regression models were developed for predicting the concentrations of total THMs and total HAAs, and can provide satisfactory estimations of the concentrations formed under the chlorination conditions studied.

\section{AKNOWLEDGEMENT}

The authors would like to thank Dr Maria N. Kostopoulou, for her scientific assistance.

\section{REFERENCES}

Cooper W.J., Zika R.G. and Steinhauer M.S. (1985). Bromide oxidant interactions and THM formation: a literature review, J. Am. Water Works Assoc., 77, 116.

Cowman G.A. and Singer P.C. (1996), Effect of bromide ion on haloacetic acid speciation resulting from chlorination and chloramination of humic substances. Environ. Sci. Tech., 30, 16-24.

Eaton A. (1995), Measuring UV-absorbing organics: a standard method. J. Am. Water Works Assoc., 87, 86-90.

EEC (1998), Council Directive 98/83/EC of 3 November 1998 on the quality of water intended for human consumption, Official Journal of the European Communities, L 330/32, 5.12.98.

EPA (1996), Drinking Water Regulations and Health Advisories, http://www.epa.gov

Golfinopoulos S.K., Xylourgidis N.K., Kostopoulou M.N. and Lekkas T.D. (1998), Use of a multiple regression model for predicting trihalomethane formation, Wat. Res., 32, 2821-2829.

Korshin G., Li C. and Benjamin M. (1997), The decrease of UV absorbance as an indicator of TOX formation, Wat. Res. 31, 946-949. 
Lekkas T.D. (2003), Occurrence and Regulation of Chlorination By-Products in Drinking Water. In The Handbook of Environmental Chemistry, Vol. 5 Haloforms and Related Compounds in Drinking Water, Otto Hutzinger, Editor-in-Chief; Springer: Bayreuth, Germany, pp.193-214.

Nikolaou A., Kostopoulou M. and Lekkas T. (1999), Organic By-products of Drinking Water Chlorination: a Review, GLOBAL NEST: The International Journal, 1, 143-156.

Nikolaou A.D., Lekkas T.D., Kostopoulou M.N., Golfinopoulos S.K. (2001), Investigation of the behavior of haloketones in water samples. Chemosphere 44, 907-912.

Nikolaou A., Lekkas T., Golfinopoulos S. and Kostopoulou M. (2002a), Application of different analytical methods for determination of volatile chlorination by-products in drinking water, Talanta, 56, 717-726.

Nikolaou A., Golfinopoulos S., Kostopoulou M. and Lekkas T. (2002b), Determination of haloacetic acids in water by acidic methanol esterification-GC-ECD method, Wat. Res., 36, 1089-1094.

Nikolaou A., Arhonditsis G., Golfinopoulos S. and Lekkas T. (2002c), Predicting the formation of trihalomethanes and haloacetic acids in surface waters by linear regression models, Epidemiology, 13, 172.

Nikolaou A.D., Lekkas T.D. and Golfinopoulos S.K. (2004), Kinetics of the formation and decomposition of chlorination by-products in surface waters, Chemical Engineering Journal, 100/1-3, 139-148.

O’Dell J., Pfaff J., Gales M. and McKee G. (1984), Test Method: The determination of inorganic anions in water by ion chromatography, Method 300.0, USEPA, Environmental Monitoring and Support Laboratory, Cincinnati OH 45268, EPA-600/4-84-017.

Pielou E.C. (1984), The Interpretation of Ecological Data: a primer on classification and ordination, John Wiley and Sons, New York, 133-175.

Richardson S. (2003), Disinfection by-products and other emerging contaminants in drinking water, Trends in Analytical Chemistry, 22, 10, 666-684.

Rook J.J. (1974), Formation of haloforms during chlorination of natural waters. Water Treatment Examination 23, 234-242.

Singer P.C. (1994), Control of disinfection by-products in drinking water, J. Env. Engineer., 120, 727.

WHO (1995), Desinfection de l' eau, Local authorities, health and environment briefing pamphlet series, 3.

Zar J.H. (1984), Biostatistical analysis, Prentice-Hall Inc, Englewood Cliffs, New Jersey. 